\title{
Las rentabilidades del arte como motivo para la inversión: preferencias de compra en tiempos de COVID-19
}

\section{Art Returns as a Motivation for Art Investment: Purchase Behavior in Times of COVID-19}

Ana Vico Belmonte

Universidad Rey Juan Carlos, España ana.vico@urjc.es https://orcid.org/0000-0002-2043-8881

Arturo Sánchez-Vasconcellos Méndez Economista especializado en Mercado del Arte arturovascon1996@gmail.com

https://orcid.org/0000-0002-8653-7989

\section{RESUMEN}

La evolución del mercado del arte y su consiguiente modelo de negocio ha generado importantes revalorizaciones en los bienes artísticos y de colección, confiriendo al arte un fuerte valor financiero y de inversión. Esta tendencia fomenta la globalización del mercado, que pasa a ser visto como una fuente de diversificación financiera, requiriendo de una mayor 
organización en la compraventa de estos bienes. Por ello, las iniciativas inversoras de las SICAV de los fondos de inversión en arte, así como nuevos modelos de inversión aupados por el desarrollo tecnológico, pronostican nuevos drivers y diversos escenarios, todo ello redibujado por la irrupción de la COVID-19 y sus repercusiones en años venideros.

Palabras clave: inversión en arte, fondos de inversión, valor refugio, COVID-19, passion investments, historia económica.

Códigos JEL: B10, L82, Z11.

\section{ABSTRACT}

The evolution of the art market and its consequent business model have generated important revaluations in fine arts and collectibles, conferring art a strong financial and investment value to art. This trend encourages the market's globalisation, which is now seen as a source of financial diversification, requiring a greater organisation in the buying and selling of these artefacts. For this reason, the investment initiatives of the SICAVs of art investment funds, as well as new investment models driven by technological development, predict new drivers and different scenarios, all of which will be redrawn by the emergence of COVID-19 and its repercussions in the years to come.

Keywords: Art investment, art fund, shelter value, COVID-19, passion investments, Economic History.

JEL Codes: B10, L82, Z11.

\section{INTRODUCCIÓN}

El mercado del arte ha crecido de manera significativa en las últimas décadas, convirtiéndose en un sector importante dentro de las llamadas passion investments, las cuales, además de un retorno financiero, proporcionan a su vez un retorno emocional. Dentro de este tipo de inversiones, el arte representa el $25 \%$ del total. Según el informe Art Market de 2020 de Artprice, las ventas totales de arte y antigüedades alcanzaron los 64.000 millones de euros en 2019, mostrando una tendencia positiva en la última década, incluso superando más rápidamente que otros sectores la crisis 
económica originada en 2008 y solventando las dificultades provocadas por la crisis sanitaria de 2020, gracias a su eficacia en la digitalización mayoritaria de sus canales de venta (Pérez-Calero-Sánchez, 2011).

Este crecimiento, unido a los múltiples atractivos que ofrece el arte como inversión, ha hecho que inversores expertos y amateurs hayan diversificado sus fondos de inversión en pro de la adquisición de obras de arte y otros bienes de colección. Entre los principales motivos que atraen a los inversores se encuentran, en primer lugar, la creencia, no siempre plausible (Vico et al., 2015), del arte como valor refugio, pues si bien sus precios se mantienen en una tendencia de crecimiento sostenido, solo las obras de alta calidad, generalmente de grandes artistas plenamente consolidados, que alcanzan un volumen de demanda constante, pueden llegar a representar un valor refugio incluso en situaciones de incertidumbre y recesión económica, dado que su demanda no se desvanece. Frente a ello, el mercado también mantiene escenarios con otras opciones, pues el arte contemporáneo de artistas emergentes, aún no consolidados, supone una inversión de tipo más especulativo, ofertando obras que no requieren un gran desembolso debido a su menor cotización pero que a futuro plantean una potencial rentabilidad en su venta a largo plazo, tras la consagración del artista en el mercado.

Nos centramos en este estudio en el arte como una opción de inversión con bajos tipos de interés y rentabilidad, donde se buscan revalorizaciones más rápidas que, como mínimo, conserven su valor en el tiempo. Al mismo tiempo, el producto artístico reporta al comprador imagen y goce estético más allá de la rentabilidad, aspecto que permite disfrutar de la inversión mientras se revaloriza; además, la escasa correlación del mismo con otros activos como las acciones y los bonos lo convierten en un factor a tener en cuenta a la hora de diversificar una cartera.

Estas razones nos llevan a estudiar el mercado del arte y sus productos como inversiones eficientes, atendiendo eso sí a ciertas particularidades que detallaremos y sintetizaremos para la mejor comprensión de las cualidades del sector en el ámbito económico. Este hecho es demostrado en las cifras, pues ciertamente las obras de arte siempre han sido productos puestos en venta, pero nunca de una forma tan clara como desde el último cuarto de siglo XX, cuando cada día más los mercados se han visto fortalecidos con más posibilidades de adquisición de este tipo de passion investments, convirtiéndose en grandes promotores de productos financieros y llegando 
a desarrollar fondos de inversión con activos artísticos, que seducen tanto como los de renta fija al prometer ganancias de $11 \%$ anual. Es así como el arte se ha revelado como una inversión de futuro que, a pesar de las dificultades económicas actuales, continúa apreciándose como un valor en alza.

Actualmente, el mercado de bienes artísticos y de colección se ha convertido en foro de intercambios constantes de obras que no pierden su valor, sino que lo incrementan, al igual que su demanda. Sobre ello, el profesor y economista Bruno Frey desarrolló importantes estudios en la economía del arte, postulando que la bajada de precios en el arte va parejo a una menor calidad artística (Frey, 2005; Frey \& Pommerehne, 1989; Frey et al., 2004). Según este autor, el público concibe la rentabilidad del arte como mucho más alta de lo que es realmente, debido sobre todo al boom de las subastas de arte y los remates alcanzados entre los años 1987-1989, cuando los inversores de arte japoneses pugnaban por las obras impresionistas y postimpresionistas, creyéndolas revalorizaciones eternas, con precios que nunca dejarían de subir, lo que ya se demostró como falso. Sin embargo, muchos coleccionistas adquieren arte sin estar motivados por un ánimo de lucro, por lo que se comportan de forma anómala como inversores. A propósito de ello, el mencionado autor matiza lo siguiente:

[...] hay pruebas de que los coleccionistas privados están sujetos al efecto dotación (una obra de arte propia se valora por encima de lo que se estaría dispuesto a pagar por adquirirla si no se tuviese), y al efecto de coste oportunidad (la mayor parte de los coleccionistas no toman en cuenta el rendimiento de usos alternativos de los fondos invertidos en arte) (Frey, 2005, p. 163).

Ante la rigidez de la oferta de arte y coleccionismo, todo aumento de la demanda, aunque al comienzo se salde con una descompensación por exceso de ella, a medio plazo elevará los precios, evitando que el mercado se balancee y asegurando a los proveedores que el costo de la subida no superará los beneficios, es decir, no habrá que retornar a precios de años anteriores, estrategia de equilibrio que resulta siempre coyuntural.

Todo ello hizo plantear a autores como Baumol (1986) la idea de que la inversión en arte resultaba como un juego aleatorio de esperanza cero, y que la tasa de retorno de los cuadros es menor que la de la inversión en activos financieros, dado el mayor riesgo del mercado artístico, si bien las obras de arte también proporcionan un beneficio psíquico derivado de la posesión y observación de ellas. Por ello, a modo de conclusión, Baumol 
deduce que en el mercado del arte no existe nada equivalente a precios a largo plazo, ni tampoco fuerzas que conduzcan al mercado hacia estos. Sin embargo, reflexionando sobre el trabajo de este autor se plantea una problemática: si los precios en el mercado de valores siguen un paso aleatorio y en consecuencia el valor de la información es cuanto menos escaso, en lo que refiere al mercado del arte y el coleccionismo el inversor difícilmente podría obtener nada del análisis de los datos sobre las ventas y los precios de las obras, por lo que la inversión allí se trataría de un lance aleatorio, en el que la información no tendría valor económico.

Es más, si nos basamos en las investigaciones previamente desarrolladas por Reitlinger (1970), que el propio Baumol analizó, sobre estudios del mercado de Londres, hallaríamos que las obras de arte ni siquiera han duplicado su precio en términos reales en dos siglos y los compradores han recibido una tasa de retorno mínima por la reventa de sus adquisiciones, tanto más si tenemos en cuenta que Baumol no consideró los costes de intermediación, que en este mercado no deben despreciarse. Entendemos pues que tales postulaciones no se mantienen, tal y como nos proponemos demostrar a lo largo de estas páginas.

Al analizar este mercado, no debemos olvidar que la obra de arte es única, y por ello tiene diferencias con los activos financieros de propiedad de individuos independientes que actúan en un mercado perfectamente competitivo. A ello hay que añadir que el precio de venta no suele ser público, por lo que no existe como en los activos financieros un precio de referencia (true price) que todos reconocen como de equilibrio a largo plazo. Solo en casos muy concretos las obras de arte pueden producir beneficios económicos sin haber sido vendidas (fotografías, estudios científicos, préstamo para exposiciones temporales, derechos de publicaciones, etc.).

\section{ANTECEDENTES Y AGENTES DEL MERCADO}

La crisis económica de la primera década del siglo XXI trajo consigo un fenómeno que demostró la importancia, cuando se cumplía, del arte como valor refugio. Cuando la economía funciona correctamente, el arte cambia de manos con facilidad y frecuencia, generando liquidez. Pero en épocas de contracción económica los propietarios de obras importantes se muestran reticentes a desprenderse de ellas, en espera de períodos benévolos en los 
que se demande y rentabilice más su venta. A diferencia de los activos financieros, la rentabilidad de una obra de arte se asienta, además de en su estabilidad como inversión, en su estimación estética, así como en el prestigio que aporta tener una obra maestra en propiedad (Lawlor, 2020).

Así, cuando las bolsas de todo el mundo cayeron en 2008, activos como los inmuebles vieron estancado su crecimiento y los rendimientos de la economía en general se redujeron, con lo que se comenzó a percibir el arte como una opción de diversificación de adquisiciones, que permite conseguir una rentabilidad aceptable cuando otros activos caen o, al menos, reducir el desplome de la cartera de compras. Por ello, los inversores y grandes patrimonialistas comenzaron a contratar servicios de banca orientados a la gestión de patrimonios artísticos, a la par que aumentaron los fondos de inversión en arte.

Sorprendentemente, desde el inicio de dicha crisis financiera, las ventas de arte actual y contemporáneo en pintura y escultura se resintieron, pues resultan las más arriesgadas ante el desconocimiento de los artistas aún emergentes, mientras que otros sectores, como el de la obra gráfica y la fotografía, con precios más accesibles, aumentaron sus ventas. Pero la situación afectó a todo tipo de compradores y los efectos en el mercado del arte perturbaron más al tipo de producto que se adquiría que a los sectores en general. Todo ello debido a que, como productos dentro de su mercado, las obras de arte, incluso de un mismo autor y período, no son productos homogéneos, y por tanto resultan sustitutivos imperfectos, generando una demanda individualizada para cada activo.

La disminución de los ingresos discrecionales conllevó una reducción de la adquisición de obras de arte, pero el mercado salvó la situación con dos estrategias, tan diferentes como efectivas. Por un lado, se produjo un "efecto sustitución" por el cambio en las preferencias de compra de los coleccionistas habituales, en ese momento con mayores dificultades económicas respecto de otros bienes más asequibles, manteniendo la consideración del arte como una inversión alternativa (Vico \& Fuente, 2018). Por otra parte, se fomentó el "efecto llamada" a nuevos coleccionistas que pudieran suplir a aquellos que, ante la crisis, habían dejado de adquirir arte, de forma que la ausencia de demanda no provocara una caída de precios, aunque inevitablemente la hubo en los primeros albores del período de recesión.

Es así como, ya en 2010, las inversiones de países nada habituales dentro del sector, como China, Rusia, India y Emiratos Árabes, registraban 
importantes compras de arte, incluso en los mercados más paralizados o en bienes que representan una inversión de riesgo. Estos nuevos coleccionistas y gestores de fondos de inversión, interesados en nuevas alternativas de compra, se centraban en la obra gráfica contemporánea, uno de los sectores más volátiles, pero con más liquidez del mercado. Mientras, los coleccionistas más tradicionales habían reducido su volumen, representando una demanda menor que amenazaba con una caída de precios y que, al reducir las compras, terminó focalizándose en obras antiguas de alta calidad, una inversión conservadora muy recurrente en momentos de crisis, pero que llegó a alcanzar grandes desembolsos.

Según los informes Artprice de 2008 y posteriores, las regiones con un mayor índice de crecimiento fueron India, China y los países del Próximo Oriente, junto con Rusia, los cuales protagonizaron dentro del mercado de subastas internacional grandes remates en la adquisición de passion investments, entre las que se incluyen el arte, los vehículos y barcos de lujo, vinos y deportes de alta gama, viajes exóticos de alto perfil, salud y bienestar. Sin embargo, existe una clara diferencia entre las inversiones realizadas en bienes artísticos o de colección, los cuales son comercializados como productos de inversión, y el resto de las materias que son consideradas como bienes de consumo; prueba de ello es que las fundaciones relacionadas con el arte y los inversores profesionales en este tipo de bienes comparten espacios y actividades cada vez más frecuentemente. En cuanto a las preferencias de inversión, el mercado de arte contemporáneo podría creerse que es inestable y cambiante, dada la importancia que tienen las modas pasajeras en él, y en parte es así. No obstante, durante las últimas décadas este mercado ha demostrado ser tan sólido como el de bienes artísticos antiguos o del período moderno, con cifras que evidencian su potencial, según los informes Hiscox de 2020 y anteriores.

Desde el punto de vista de una inversión en la que se espera obtener beneficios, resulta más arriesgado adquirir obras de artistas emergentes que de aquellos plenamente consagrados, pero el mercado ha demostrado que, en lo que refiere a la pintura contemporánea, si se invierte con cautela y realizando estudios previos sobre el artista, su carrera y su cotización, la compra puede llegar a generar intereses de $+7,6 \%$ en un plazo medio de 8 años. Cierto es que es un sector con un problema de exceso de oferta, pero no quiere decir que ello actúe negativamente en el precio, sino simplemente que la mayoría de los artistas siguen vivos y por lo tanto produciendo. 
Aun así, se puede afirmar que el mercado de la pintura contemporánea es eficaz, rentable y asequible a un amplio abanico de compradores (dependiendo del conocimiento del artista). Actualmente, el pop art, la abstracción y el street art son los estilos más demandados dentro del sector de la pintura, con una procedencia mayoritariamente norteamericana, pues es donde se sitúan los artistas más representativos. China presenta unos datos similares en cuanto a creatividad, pues desde mediados del siglo pasado ha sido cuna de grandes artistas actualmente muy cotizados. Por otro lado, África comienza a emerger y tomar lugar dentro del mercado del arte contemporáneo, gracias a la visibilidad dada por las exposiciones realizadas principalmente en Francia, lo que la sitúa como una región interesante en la que invertir, con precios accesibles, que previsiblemente se elevarán.

Es así como Artprice, en sus informes de 2020 y anteriores, sitúa el mercado contemporáneo en una tendencia al alza, con una subida de 18,5\%, representando $15 \%$ del número de ventas totales de arte y superando la venta de obras de los maestros clásicos y del arte del siglo XIX. Ciertamente, aún no alcanza el volumen de ventas del arte de posguerra o del arte moderno, que representan el $68 \%$ del mercado. Pero es un mercado complejo y cambiante, en gran parte debido a su alta dependencia de las modas, contando con la presencia de determinados artistas catalogados como nuevos clásicos, que se sabe son valores seguros. Resulta así un mercado más dinámico y cambiante, que en ocasiones da la imagen de ser algo caótico, pues está vivo, como sus artistas, y ofrece cada día nuevos talentos por descubrir. De hecho, anualmente se compran y se venden cerca de 70.000 obras de arte contemporáneo en el mundo, principalmente en Estados Unidos, país líder dentro del arte contemporáneo, y en el mercado asiático, que está creciendo explosivamente y diversificándose, gracias a plazas de venta tan efectivas como Hong Kong, la cual se está revelando como uno de los centros neurálgicos del arte contemporáneo mundial.

\section{Oferta de obras de arte}

El concepto de valor de mercado de un bien artístico o de colección descansa sobre cierta lógica económica, que enlaza directamente con el hecho de que en realidad todo coleccionismo tiene un matiz de inversión, pues nadie paga un determinado precio por un objeto, sabiendo que podría localizarlo en el mercado en un margen de tiempo prudencial, en condiciones análogas, por un precio similar o inferior. Incluso en el caso del gran 
coleccionista de arte motivado por la pasión y no por la inversión, el plano económico también le influye en su toma de decisiones.

El arte como inversión presenta unas características muy particulares, que hay que tener muy en cuenta a la hora de invertir en él, ya que las obras de arte no son bienes fungibles, es decir, a diferencia de las acciones, bonos y demás productos financieros, cada obra de arte es única y no puede ser reemplazada por otra. En ese sentido, al comprar acciones de una empresa no se especifica la acción particular que se adquiere, mientras que en el arte cada precio que se paga por un bien corresponde, por ejemplo, a un Matisse, Rothko, Stern o Picasso específico, lo cual condiciona el precio de una obra de arte de manera fundamental, ya que, en ocasiones, el propio nombre del artista lleva por sí solo aparejado un rango de precios; también es cierto que dentro de la obra del autor cada época cotiza de una manera distinta, pues es la calidad artística lo que acumula el mayor peso ponderable en la carga del precio. La obra de arte original y única es lo que los inversores en arte compran al especular en el sector, y es esa rareza lo que justifica el alto precio (Baltayan, 2020).

Además, en el mercado del arte existe una importante diversidad de productos (pintura, escultura, performance), más que en otros mercados, lo que provoca que cada bien tenga un comportamiento distinto en cuanto a su rendimiento. Ni siquiera dentro de un mismo sector tienen la misma revalorización cuadros de autores y cronologías diferentes, cuanto menos aún porcelanas u otros objetos de las artes decorativas, lo que introduce nuevos factores y más complejos a la inversión, pero que, de todos modos, a su vez facilitan la diversificación.

$Y$ es que el factor subjetivo del arte es otra característica que no puede obviarse al considerar la inversión. El arte no tiene un valor monetario intrínseco, y el precio de una pintura o escultura se centra en lo que el coleccionista esté dispuesto a pagar. Por ello, el mercado está muy condicionado a las tendencias de cada momento, que pueden depender de modas, exposiciones o efemérides. Artistas o movimientos que durante una época alcanzan precios altos pueden caer de manera considerable tiempo después, tanto en precios como en volumen de ventas, como ha ocurrido en los últimos años con los maestros ingleses. Esto le imprime al mercado una incertidumbre poco atractiva para los inversores, considerando al mercado, especialmente el contemporáneo, excesivamente arriesgado e imprevisible. 
Al analizar la rentabilidad de una obra de arte, destacamos aquí la falta de liquidez, debido a la dificultad de venta (estudio de obras, leyes, movilidad), y su lenta revalorización (especialmente grandes maestros) como los aspectos más desmotivantes para la inversión. Por esto, dentro del mercado del arte se emplea el concepto económico de primas de iliquidez, que explica la fuerte correlación positiva entre la falta de liquidez y los rendimientos a lo largo del tiempo, entendiendo que el mercado compensa a los inversores que poseen activos menos líquidos aportando una rentabilidad mayor que otros activos más líquidos, como las acciones, compensando así el problema de la iliquidez a la que se enfrentan las obras de arte (Karim, 2018). A propósito de ello, encontramos un estudio realizado por Citi Private Bank (2020), basado en datos de la empresa Masterworks.io, inversora en arte, donde se destaca una rentabilidad media anual de las obras de arte entre 1985 y 2018 del 5,3 \%, menor que otros retornos alcanzados por las bolsas en mercados desarrollados durante ese mismo período $(9,8 \%$ ), y por debajo también de la renta fija (6,5\%). Según estos datos, el arte contemporáneo fue el sector del mercado con mejor promedio anual (7,4\%), por encima del impresionismo (5\%). Teniendo en cuenta estos datos, la inversión, aunque no aportase los mismos retornos, seguiría siendo rentable, por lo que sería muy conveniente introducir estos activos en las carteras para alcanzar una mayor diversificación, ya que es un activo de inversión comparable a los más comunes, como se observa en la figura 1.

Figura 1. Preferencias de inversión en arte

Fuente: Citi Private Bank (2020)

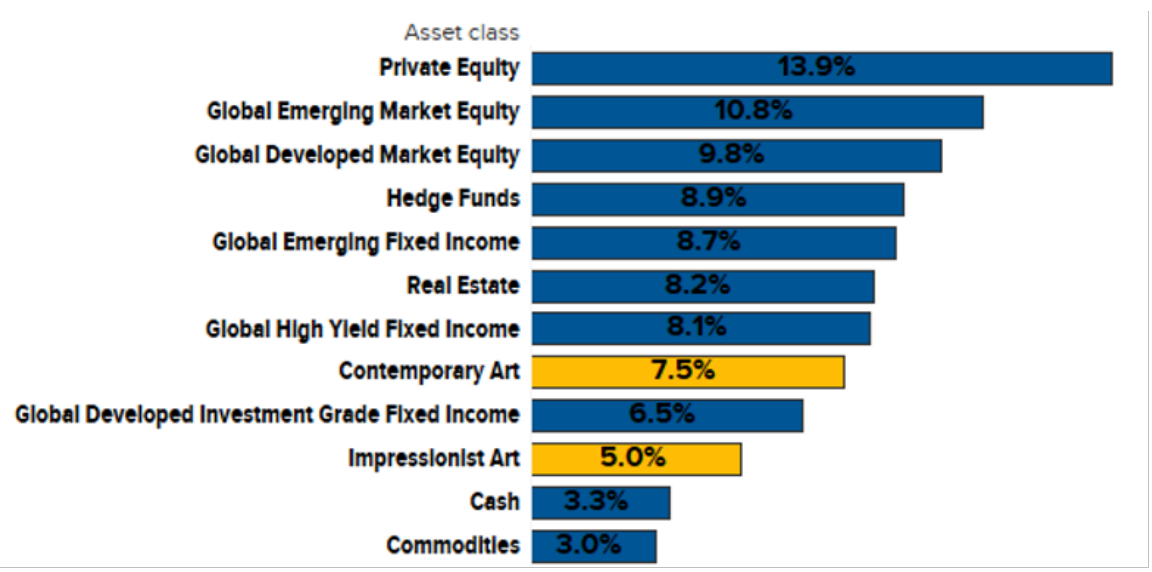

En resumen, las obras de arte presentan unas características muy particulares que las diferencian de otros activos financieros, y que han de ser tenidas en cuenta antes de invertir, para poder controlar al máximo todos 
los aspectos de la inversión y saber sacarle la máxima rentabilidad posible (Parsons, 2017).

Las razones por las que parece preferible el sector de arte contemporáneo radican básicamente en su estética, y en la constante renovación de obras y artistas, adaptándose a los estilos decorativos más modernos y sofisticados, al tiempo que se comercializa con libertad de movimiento entre países sin restricciones aduaneras. Por el contrario, presenta más riesgo para la inversión que la obra antigua ya asentada dentro del mercado, con unos precios muy delimitados $y$, sobre todo, con unos autores plenamente consolidados. Y es que el mercado de obras antiguas tiene sus propias peculiaridades, siendo seguramente la primera de ellas que ya no podemos hablar de un único mercado del arte, sino de diversificación en varios mercados representados por países que, según su legislación vigente y perfil cultural, presentan características diversas, por lo que cuentan con sectores (antigüedades, numismática, bibliofilia, pintura contemporánea, etc.) poco homogéneos en desarrollo y éxito, según los intereses de su propios coleccionistas. Las legislaciones son las que marcan las posibilidades de cada mercado y aquellas excesivamente restrictivas, como la española, han provocado que este se convierta en una burbuja, que ciertamente ha tratado de abrirse $y$, de hecho, poco a poco parece llevar esta tendencia, aunque aún no es un ejemplo de libre mercado, como podría ser por ejemplo el británico.

\section{Demanda de obras arte}

Existen muchas razones para adquirir arte, pero los agentes del mercado destacan cuatro principales: disfrute personal, prestigio, ganancias económicas y ventajas fiscales. Centrados como estamos en el plano inversor, nos interesan especialmente aquellas relacionadas con las motivaciones económicas y que incentivan a invertir en arte para, por ejemplo, diversificar carteras, maximizar su rentabilidad, minimizar la volatilidad y lograr ventajas fiscales.

La diversificación dentro de las carteras de inversión resulta fundamental para equilibrar el riesgo, de modo que si un segmento se retrasa, el impacto financiero se minimiza tanto como sea posible. $Y$ el arte favorece tal diversificación porque presenta una correlación baja con otros activos financieros, por lo que es menos susceptible a ciclos económicos y desequilibrios. Según algunas investigaciones, como los informes Artprice y Hiscox de 2020, el coeficiente de correlación entre los precios del arte y el S\&P 500 se encuentra entre $-0,03$ y 0,19 , una correlación relativamente baja que 
Tabla 1. Matriz de correlación de la rentabilidad anual a 40 años por clase de activos explicaría que cuando los mercados de renta variable disminuyen, es más probable que las obras de arte retengan su valor. El mejor ejemplo se produjo durante la crisis financiera de 2007 a 2009, cuando hubo una disminución de entre 26 y $28 \%$ en los precios de los 100 mejores artistas, mientras que el S\&P 500 disminuyó $56 \%$. Además, el arte presenta correlaciones positivas con activos de riesgo tales como la renta variable americana, y un balance positivo de rentabilidad vs. riesgo a lo largo del último medio siglo, tal y como refiere el informe realizado por Citi anteriormente mencionado, donde se llega a señalar que existen algunas correlaciones entre las categorías de arte y las clases de activos tradicionales: por ejemplo, el arte impresionista y los viejos maestros están altamente correlacionados con activos seguros como bonos o bienes raíces, mientras que el contemporáneo está más correlacionado con acciones y productos básicos, más propensos al riesgo. En la tabla 1 se muestran las correlaciones a 40 años de diferentes opciones de inversión.

\begin{tabular}{|c|c|c|c|c|c|c|c|c|c|c|c|c|c|c|}
\hline Asset Class & S\&P 500 & $\begin{array}{c}\text { DiA } \\
\text { Equilias }\end{array}$ & $\begin{array}{c}\text { EM } \\
\text { Equites }\end{array}$ & $\begin{array}{l}\text { 10-Year US } \\
\text { Tsy Note }\end{array}$ & $\begin{array}{l}\text { DM Inv } \\
\text { Grado Debs }\end{array}$ & $\begin{array}{l}\text { High Vieid } \\
\text { Dobi }\end{array}$ & EM Dear & $\begin{array}{l}\text { Hedge } \\
\text { Funds' }\end{array}$ & $\begin{array}{l}\text { Privale } \\
\text { Equiny }\end{array}$ & Res Estate & Cast & $\begin{array}{l}\text { Commo } \\
\text { laroad } \\
\text { Indexi) }\end{array}$ & Goid & Ant \\
\hline SAP 500 & 1 & 0.92 & 0.64 & $-0,02$ & 0.33 & 0.34 & 0.28 & 0.72 & 0.64 & 0.5 & 0.08 & 0.05 & -0.21 & 0.11 \\
\hline Developed Market (DM) Equities & 0.92 & 1 & 065 & 4.12 & 0.28 & 0.57 & 0.28 & 0.76 & 0.81 & 0.6 & 0.07 & 0.12 & -0.09 & 0.16 \\
\hline Emerging Markat (EM) Equities & 0.42 & 0.64 & 1 & .0 .37 & -0.08 & 0.57 & 0.09 & 0.55 & 0.66 & 0.5 & -0.07 & 0.49 & 0.12 & 0.16 \\
\hline 10-Vear US Treasury Note & 002 & 0.12 & 0.37 & 1 & 0.78 & 0.01 & 0.59 & 0.00 & 0.25 & -0.1 & 0.16 & -0.38 & 0.14 & 0.02 \\
\hline DM Investment Grade Debt & 033 & o 28 & -005 & 0.76 & 1 & 0.46 & 0,78 & 0.47 & 0.15 & 0.3 & 0.28 & -0.35 & -0.30 & -000 \\
\hline Hight Yled Debt & 0.84 & 0.67 & 0.57 & 0.01 & 0.46 & 1 & 0.29 & 0.68 & 0.64 & 0.6 & -0.08 & 0.06 & -0.15 & -0.28 \\
\hline EM Deot & 0.28 & 0.28 & 0.09 & 0.59 & 0.78 & 0.29 & 1 & 0.59 & 0.20 & 0.3 & 0.53 & -0.28 & 0.00 & 0.09 \\
\hline Hedge Funde" & 0.72 & 0.76 & 0.55 & 0.00 & 0.47 & 0.68 & 0.59 & 1 & 0.74 & 0.8 & 0.48 & 0.11 & 0.03 & 0.02 \\
\hline Private Equity & 0.34 & Q81 & 0.68 & .025 & 0.15 & 0.84 & 0.20 & 074 & 1 & 08 & 0.07 & 012 & 0.06 & 0,01 \\
\hline Real Estate & 0.50 & Q64 & 0.53 & $\$, 07$ & 0.30 & 0,64 & 0.25 & 0.58 & 0.77 & 1 & $-0,03$ & 0.07 & 0.03 & 0.02 \\
\hline Cesh & 0.08 & 0.07 & -0.07 & 0.16 & 0.28 & -0.08 & 0.53 & 0.48 & 0.07 & -0.03 & 1 & -0.08 & 0.36 & 0.18 \\
\hline Commoditus (broas index) & 0.11 & Q.16 & 0.15 & 0.02 & -0.09 & .0 .28 & 0.09 & 0.02 & 0.01 & 0.02 & 0.18 & 1 & 0.36 & 0.27 \\
\hline Gold & .021 & -0.09 & 0.12 & 0.14 & 0.30 & -0.15 & 0.18 & -0.09 & 0.06 & 0.00 & 0.03 & 0.36 & 1 & 0.1 \\
\hline An & 0.11 & 0.16 & 0,12 & 0.02 & -0.09 & -0.26 & 0,09 & 0.02 & 0.01 & 0.02 & 0.18 & 0.3 & 0.1 & 1 \\
\hline
\end{tabular}
rendimientos aceptables. Ante la necesidad de conocer datos fiables y contrastables de los precios del mercado han aparecido en las últimas décadas una serie de índices que permiten equiparar los valores del arte a otros sectores. Entre estos destaca el resultante de la absorción por parte de Sotheby's de los índices Mei Moses, que otorgan una profunda visión del mercado en un trabajo conjunto, basado en la venta repetida (tomando el valor de mercado de un activo concreto, que ha sido vendido un mínimo de dos veces, con el fin de estimar el cambio que experimenta el valor de una pintura en el tiempo), y proporcionando una retrospectiva de la evolución del mercado 
a largo plazo, resaltando los espacios en los que el arte genera rendimientos mayores que los activos tradicionales. Fruto de esta unión encontramos gráficos tan ilustrativos sobre el progreso del mercado como el que mostramos a continuación, donde se aprecia que el índice ha seguido una tendencia alcista, con escasas caídas, desde 1950 hasta la actualidad, aportando retornos considerables incluso desde los años noventa en adelante (figura 2).

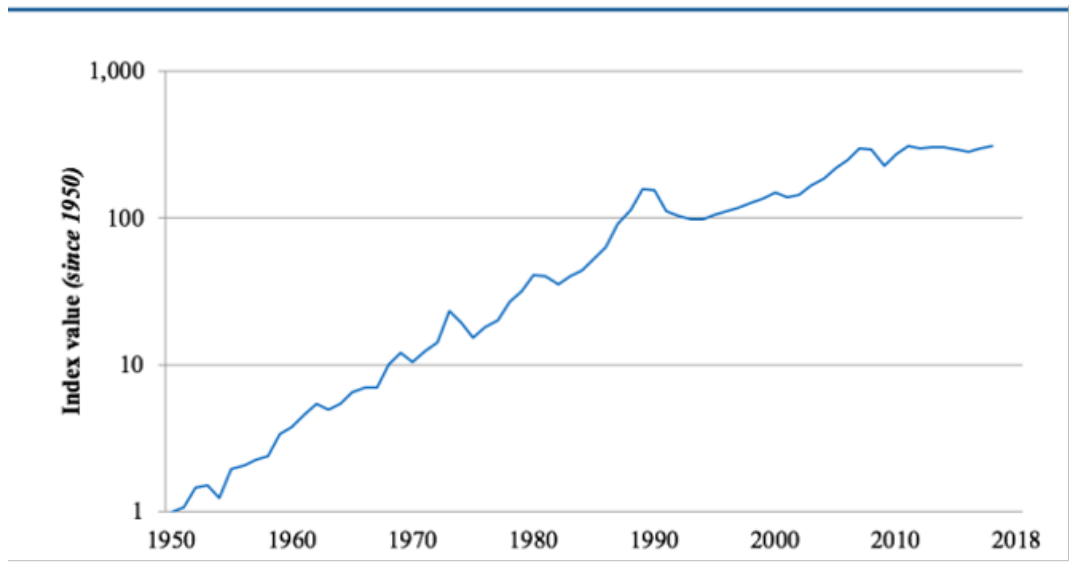

Otro índice destacado y muy relevante para el seguimiento de la rentabilidad y confianza del mercado es el Artprice100, que incluye a los cien artistas más relevantes del mercado, ponderados por su promedio de ventas en los últimos cinco años, aunque cumpliendo un criterio de liquidez de al menos diez obras de calidad comparable vendidas cada año. Analizando el gráfico, se percibe que durante 18 años Artprice 100 creció $360 \%$, generando un rendimiento promedio anual de $8,9 \%$, mayor que otros activos financieros durante ese mismo período (el S\&P 500 arrojó un 3,4 \%), mostrando una tendencia estable y alcista del segmento más destacado del mercado (figura 3).

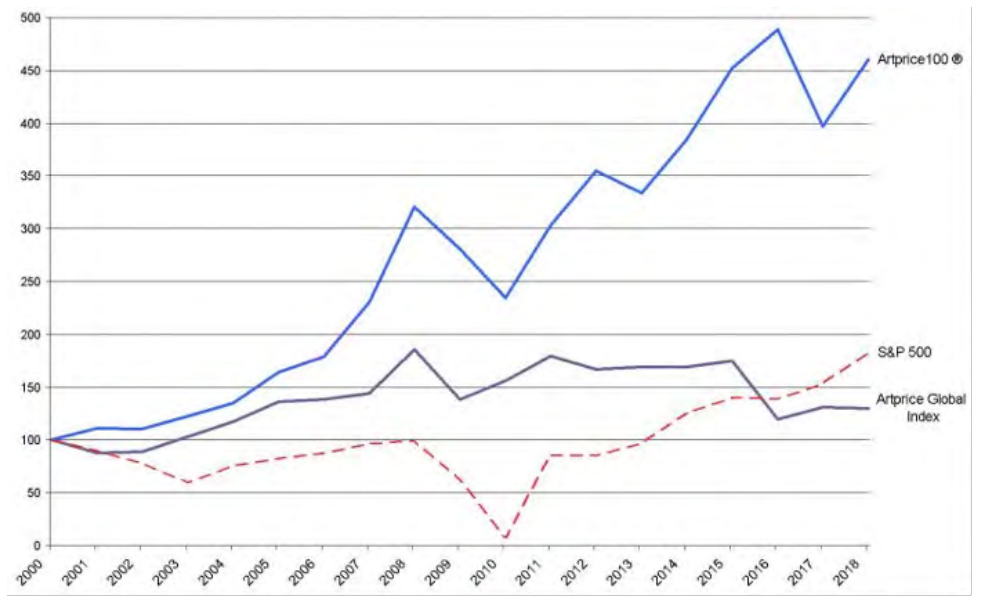

Figura 2. Índice de Sotheby's y Mei Moses: 1950-2018

Fuente: tomado de https://www sothebys.com/en/the-sothebysmei-moses-indices.

Figura 3. Índice de Artprice $100^{\oplus}$, S\&P 500 y Artprice Global
Fuente: tomado de https://www artprice.com/artmarketinsight/ artprice-launches-its-blue-chipart-market-index-artprice 100designed-for-financiers-andinvestors-2. 
De todos estos informes se extrae que el arte tiene, además, un comportamiento interesante en períodos de alta inflación o inflación creciente, rindiendo más que otros activos financieros en el intervalo comprendido entre 1973 y 2012, cuando aportó un $18 \%$ frente al $5 \%$ de los bonos y al $13 \%$ de las materias primas (Saatchi, 2016, p. 45). En este sentido, hay que recordar el uso del arte como valor refugio, atrayendo a inversores que buscan mercados con menos fluctuaciones que los mercados financieros, ya que el mismo cuenta con una volatilidad menor que otros activos en relación al devenir de la economía y conserva su valor a lo largo del tiempo, haciéndolo especialmente útil en épocas de crisis. Por ello, la rentabilidad que aporta, unida a su escasa correlación con otros activos y con la propia economía, además de su utilidad como valor refugio, hacen del arte un activo cada vez más solicitado por los inversores.

La fiscalidad es también una de las motivaciones para invertir en arte, sobre todo en determinados países anglosajones, como Estados Unidos, donde las políticas fiscales fomentan y promueven extraordinariamente su adquisición, incluso con intenciones de mecenazgo en muchas instituciones y organizaciones culturales. Uno de los beneficios fiscales más interesantes y empleados por los países es el sistema de dación, que permite pagar impuestos comprando obras de arte sin pagar la plusvalía que ha generado dicha obra. Otros beneficios pueden ser la transmisión de obras como sucesiones y donaciones y la desgravación por parte de las empresas en el impuesto de sociedades, lo que ha llevado a muchas a crear colecciones.

En definitiva, los motivos económicos para adquirir arte son numerosos, y estimulan a invertir en bienes diferentes a los activos tradicionales, con interesantes rentabilidades, además de escasa volatilidad y correlación con otros activos. Esto permite garantizar un valor refugio frente a posibles crisis, o acogerse a ventajas fiscales, más allá del propio placer visual y de disfrute de coleccionar obras de arte.

\section{CANALES DE INVERSIÓN EN ARTE}

Como se ha visto a lo largo de este estudio, el arte puede llegar a ser un interesante objeto de inversión; sin embargo, es un mercado lleno de particularidades y limitaciones (de oferta, liquidez, e incluso legislativas) que hacen de este sector un campo abonado a las excepciones y reglas subliminales. De 
los distintos modos de invertir en arte, destacan por su peso dentro del mercado los fondos de inversión, que crecieron de manera considerable a raíz de la crisis económica de 2008, así como la compra de acciones de empresas del arte, dependientes en gran medida de los mercados financieros, y, como nuevas formas de inversión, el modelo de inversión de propiedad fraccionada y el uso del arte en las collateralized debt obligation (COD).

Ante la búsqueda de rentabilidad a partir de la compraventa de obras de calidad, que obviamente son las que realmente garantizan su revalorización, y atendiendo a una demanda constante, solo este tipo de obras pueden ser atendidas como valores refugio. La problemática que presentan es el alto coste de adquisición, y justamente por ello surgen las diferentes formulaciones de compra, entre las que destacamos los fondos de inversión como el vehículo generador de carteras más recurrente, pues con ellos se divide la propiedad del bien artístico entre varios propietarios para, a través de plataformas tecnológicas y sobre la base de expertos que las adquieren en un mercado global, crear una colección en un horizonte temporal que permita, con su liquidación y venta, retornar plusvalía a los numerosos inversores que conforman la base patrimonial de estas sociedades. Son estos nuevos estilos de compra que, con grandes y numerosas aportaciones, permiten la compra de piezas excepcionales.

\section{Fondos de inversión en arte}

Los fondos de arte son fondos de inversión ofrecidos de forma privada, dedicados a la generación de rendimientos a través de la adquisición y disposición de obras de arte. Entre las actividades que realizan se encuentran la búsqueda de posibles adquisiciones, la recaudación de capital y gestión de este para el fondo, las relaciones con inversores, la muestra de la cartera del fondo a través de exposiciones y préstamos a museos o la gestión del almacenamiento y de seguros de arte.

El colapso de la burbuja de las .com, en 2001, alimentó la tendencia de los fondos de arte, ya que los inversores buscaron oportunidades alternativas fuera del mercado. Esta tendencia hacia activos alternativos reapareció a raíz de la crisis financiera de 2008, y ese fue el punto clave de su desarrollo. Según Thompson (2007): 
[...] los fondos de inversión en arte a diez años fueron lanzados entre 2005 y 2007. Gestionados por antiguos directores de las casas de subasta Christie's y Sotheby's y por expertos en dinero de Wall Street, titularizan el arte; preparan una colección de obras de arte en un solo paquete y permiten a los inversores comprar participaciones del paquete, de forma análoga a un fondo de inversión o un fondo de capital privado (p. 295).

En los últimos años ha habido un aumento significativo en la oferta de fondos de inversión de arte, algunos de los cuales ya han salido al mercado y otros siguen en proceso. Los motivos mencionados anteriormente, sumados a la particularidad de la falta de regulación que en determinados aspectos brinda el mercado del arte, punto especialmente relevante para estos fondos, han llevado a los inversores a interesarse por ellos, lo que ha generado oportunidades únicas de arbitraje que pueden ser explotadas por entidades financieras creadas con ese fin.

Los fondos son administrados por una firma profesional de asesoría o gestión de inversiones en arte, que recibe una comisión de gestión y una parte de los rendimientos entregados por el fondo. Por regla general, los administradores cobran comisiones anuales de gestión de entre 1 y $3 \%$ sobre el valor del activo neto de la cartera de arte del fondo o sobre los compromisos de capital totales realizados por los inversores, así como una comisión de rendimiento equivalente al $20 \%$ de las ganancias obtenidas a partir de la disposición de la cartera de arte. Para entrar como inversor en un fondo se establece un acuerdo de suscripción, donde se detalla el número de acciones, precio y demás detalles; generalmente, el desembolso inicial es elevado, por encima de los 250.000 dólares. Un ejemplo es Fine Art Fund Group, creado en 2001, el cual tiene diversos fondos separados, cada uno de los cuales está compuesto por un mínimo de inversión de entre USD 500.000 y 1.000.000 y por 30-40 inversores individuales o institucionales.

Pero no todos los fondos tienen las mismas características, sino que varían de uno a otro en el tamaño, duración, enfoques y estrategias de inversión o restricciones de cartera. Por norma general, cuando se venden obras de arte, un porcentaje de las ganancias netas (después de una tarifa administrativa) se distribuye entre los inversores y el porcentaje restante se reinvierte en compras de arte adicionales, hasta que se llega al límite de tiempo fijado para el fondo y las ganancias netas se dividen entre los inversores. Las estrategias de inversión son el punto donde más difieren, ya que son numerosas, y entre ellas encontramos, además de las estrategias de 
corte más tradicional, centradas en comprar y vender: el arbitraje geográfico, que busca explotar los diferentes precios de ciertos artistas en diferentes ubicaciones geográficas; las estrategias de arte regional, que se concentran en invertir en arte de una región geográfica particular (por ejemplo, arte chino); las estrategias de período, que invierten en un período particular de arte (contemporáneo, impresionista, etc.); los artistas emergentes, que por su condición tienen más potencial de rendimiento; las estrategias de apalancamiento, que implican pedir un préstamo sobre el stock en poder del fondo de arte y usar dichos recursos para adquirir obras adicionales que se espera que produzca rendimientos mayores que los costos de préstamo durante el plazo de este; las estrategias de copropiedad, que operan trabajando conjuntamente con inversores externos para compartir el riesgo de una inversión particular y proporcionar así una mayor diversificación de la cartera de inversiones del fondo artístico; o, finalmente, las estrategias de compra a granel, en las que se compran grandes lotes de arte para lograr mejores precios y menores costos de transacción, entre otras.

Hay que señalar que la mayoría de los fondos utilizan más de una estrategia simultáneamente para diversificar y obtener rendimiento de todas. Es importante señalar que estas tasas de rendimiento tienden a variar en función de las características de los artistas a los que se enfoque: aquellos fondos que tengan en cartera artistas emergentes tendrán oscilaciones de precios mucho mayores que aquellos que coleccionen obras de artistas establecidos, aunque la tendencia general suele ser combinarlos en las carteras para diversificar el riesgo y reducir dichas oscilaciones.

Luego de este análisis, captamos que los fondos de inversión resultan adecuados para el mercado del arte en tanto que aportan capital externo, favoreciendo su crecimiento y proporcionando liquidez a un mercado que suele adolecer de ella, lo que también ayuda a estabilizarlo en períodos recesivos, aunque las verdaderas ventajas vienen para los inversores que decidan participar a través de ellos. Por un lado, aunque el mercado del arte está sujeto a poca supervisión, los fondos de arte están sujetos a la regulación de la industria financiera y deben cumplir con los requisitos de divulgación inicial y periódica, así como con las disposiciones antifraude, que brindan cierto nivel de protección al inversionista. Los gestores de fondos de arte también tienen un deber fiduciario con respecto a sus inversores, lo que prácticamente no existe en las relaciones entre galeristas e inversores o casas de subastas. Proporcionan, además, diversificación y economías de 
escala al agrupar activos, y la posibilidad de exponer las obras permite aumentar su valor, favoreciendo la visibilidad de la colección, al tiempo que dan a los inversores la posibilidad de pedir prestado o adquirir obras de la colección. Las iniciativas inversoras de las sociedades de inversión de capital variable (Sicav) Anthea, Fine Art Fund, Fondo Global de Artemundi, Liquid Rarity Exchange, o las iniciativas de Saatchi Art, pronostican nuevos drivers y aportan los últimos modelos que estimularán y crearán nuevas formas de invertir en arte y futuros beneficios.

\section{Otras maneras de invertir en arte (bolsa, propiedad compartida)}

Además de los fondos de inversión, el crecimiento de la inversión en arte ha generado la aparición de nuevos instrumentos y modelos empresariales que se valen de este para generar rendimientos. Son opciones similares a las anteriormente descritas, pero que permiten la accesibilidad a inversiones de menor cuantía económica.

Un ejemplo de ello lo representa la plataforma Masterworks, que ha puesto en el mercado desde 2017 una de las propuestas más innovadoras: en lugar de pagar dos millones de dólares por una pintura, se compra una pequeña parte de ella. Esta plataforma está orientada a aquellos inversores que no quieren un gran compromiso financiero, como el que exigen los fondos de arte. El proceso es el siguiente: la empresa compra pinturas con su capital, luego se presenta a la Comisión de Bolsa y Valores para hacer una oferta pública, a partir de la cual los inversores pueden comprar acciones de una pintura, y, por último, se vende la pintura y cada inversor obtiene su parte proporcional a las acciones que tiene, descontada la tarifa de administración anual del 1,5\% más el $20 \%$ de las ganancias si la pintura aumenta de valor, resultando así un proceso muy parecido a comprar una acción en una empresa que se hace pública. La intención de la plataforma es mantener las obras entre tres y cinco años para permitir que se revaloricen, aunque en cualquier momento un coleccionista puede hacer una oferta para comprar una pintura en la que ha invertido. Algunos artistas representados en su cartera son Warhol, Basquiat, Rothko o Mitchell, y las obras se almacenan en condiciones óptimas en el puerto franco de Delaware (SánchezVasconcellos et al., 2020). En definitiva, se ofrece la posibilidad de adquirir participaciones de obras de prestigio (artistas blue-chip) sin la necesidad de hacer un gran desembolso y pudiendo vender esas acciones cuando se quiera, aportando así al mercado un enfoque más financiero. 
Estos sistemas de venta hacen que el arte esté cada vez más presente en la red bancaria, lo que ha llevado a los bancos a utilizarlo incluso como garantía. De hecho, las obras de arte se han empezado a emplear en obligaciones de deuda colateralizada (CDO), tan famosas a raíz de la crisis financiera de 2008. Una CDO es un producto de inversión estructurado que hace uso de activos generadores de flujo de efectivo, los cuales incluyen hipotecas, préstamos, bonos y deudas de tarjetas de crédito, agrupados en tramos que pueden venderse a inversores. El arte está empezando a utilizarse de este modo en préstamos respaldados por obras que funcionan como activo subyacente, puesto que los préstamos de arte han aumentado considerablemente en los últimos años, llamando la atención de las entidades financieras como activos diversificadores. Algunos expertos ya han alertado del riesgo que conlleva introducir un elemento tan particular como el arte en instrumentos tan volátiles como las CDO, a las que muchos culpan como causantes de la grave crisis financiera de hace una década.

Estos nuevos modos de inversión en arte están en proceso de expansión, y habrá que observar cómo evolucionan en los próximos años. Mientras tanto, algunos datos nos dan idea de por dónde pueden discurrir estas vías: solo el $19 \%$ de los profesionales del sector consideran que las formas de inversión fraccionada en obras de arte son interesantes para sus clientes (Deloitte, 2019), mientras que la mitad de los compradores menores de 30 años las tendría en cuenta, según el informe Hiscox de ese mismo año 2019. Por tanto, es posible observar que, aunque aquellos agentes más asentados en el mercado no vean estos modos de inversión como algo para tener en cuenta, sí es posible que las próximas generaciones de compradores los utilicen y exploren más.

\section{EL MERCADO DEL ARTE TRAS LA COVID-19}

El 2020 trajo consigo un suceso que no pasará inadvertido en la historia, la pandemia mundial que ha asolado al planeta, dejando consigo innumerables daños que desembocaron en una grave crisis económica. Al igual que en todos los sectores que forman parte de la economía, el mercado del arte se ha visto afectado, descendiendo el número de compras y aumentando el número de coleccionistas que desean vender sus preciadas piezas.

Una obra de arte puede ser un bien variable que protege el dinero, pero está claro que, aun así, ante una crisis la demanda cae y con ella los precios, aunque estos lo hacen en proporciones variables. Si se colecciona a modo de inversión, siempre hay que tener en cuenta que no todas las obras 
pueden ser consideradas como valor refugio, pero, a pesar de ello, situaciones de crisis anteriores nos han demostrado que la rentabilidad, sobre todo de antigüedades, a largo plazo es indiscutible. Por otro lado, esta situación tan desconocida ha dado lugar a una renovación del mercado tal y como lo conocíamos, rompiendo la tradición de la compra o puja presencial en el caso del mercado del arte. Ferias, casas de subasta y galerías han sacado su imaginación y perspicacia a flote, encontrando así las mejores soluciones a esta situación, como lo son las exposiciones virtuales o las subastas online.

La digitalización de las empresas del mercado del arte y los bienes de colección ha aumentado drásticamente lo que ya estaba en proceso de crecimiento. Ahora, y gracias a internet, el mercado del arte se ha globalizado por completo, permitiendo el acceso a coleccionistas y amantes del arte de todas partes del mundo, quienes con un simple click pueden hacerse con una obra que se encuentra en la otra punta del mapa terrestre. La subasta realizada por Sotheby's en julio de este mismo año demostró el potencial del mercado del arte, y cómo sigue siendo un buen momento para invertir en bienes artísticos y de colección.

El auge del mercado online ha favorecido el acercamiento de los inversores al arte, con todas las facilidades que ofrece a nivel global, alcanzando un valor total de 5.900 millones de euros, lo que representa $9 \%$ del valor total de ventas del mercado, según el Art Market Report de 2020. En el informe Hiscox de 2018 se estimaba que el mercado del arte online podría alcanzar USD 9.320 millones en 2024. Ante el nuevo horizonte postcovid, queda por ver las posibilidades de crecimiento que tendrá este mercado. Con todo, la mayor accesibilidad a través de las nuevas tecnologías e internet para la compra de todo tipo de bienes artísticos ha provocado un acercamiento de nuevos públicos durante la crisis sanitaria, que buscan diferentes fórmulas para invertir, a partir de obras antiguas o contemporáneas y dentro de diferentes parámetros de precios, dado que la obra de artistas emergentes resulta muy accesible, aunque arriesgada ante la incertidumbre sobre la carrera que recorrerá el artista; en contraste, la obra de grandes artistas ya consolidados supone otro tipo de adquisiciones. 


\section{CONCLUSIONES}

Ante las anteriormente citadas afirmaciones de Baumol (1986), encontramos que, realmente, este autor eligió un período demasiado amplio (cerca de trescientos años), por lo que evidentemente la lista de artistas más considerados, e incluso la valoración que el mercado del arte tiene de ellos, varía mucho a lo largo de ese tiempo (Vico et al., 2015). Por otro lado, Baumol elimina del estudio las obras revendidas antes de transcurrir veinte años desde su compra, sin explicación al respecto. En consecuencia, tomar un listado que comienza en 1652 y admitir solo las ventas realizadas tras al menos veinte años de posesión no puede sino distorsionar los resultados. Estas afirmaciones fueron enunciadas en uno de los artículos más citados en la literatura sobre la economía del arte, donde se analizan las peculiaridades que hacen que los precios de equilibrio en el mercado de obras de arte sean antinaturales, comparando este mercado al de activos financieros. Según el autor, la elasticidad de la oferta es "absolutamente cero" en determinados mercados, como, por ejemplo, en el de los grandes maestros fallecidos.

Por su parte, la rentabilidad de la inversión en obras de arte está condicionada por los altos costes de transacción y por una fiscalidad desigual. Una comparación de los beneficios generados por la inversión en bienes artísticos y de colección con los de otros activos financieros muestra las diferencias notables entre ellos, por las propias fluctuaciones que contemplan incluso obras de un mismo artista o período artístico. En el momento en el que los compradores limitan el precio de compra, toman una decisión similar a la que realizan si tienen que calcular la inversión en otro tipo de activo, como acciones de una compañía o bonos del Estado. La única diferencia está en que el activo arte no produce una renta monetaria, por lo que los compradores solo se trazan una expectativa de la plusvalía que la obra les puede reportar al venderla en un determinado lapso.

La obra de arte puede tomarse como un bien variable que protege la inversión, pero que está supeditado a variaciones económicas y sociales. Como inversión, los datos económicos y de ventas demuestran mejores resultados al comprar una obra de primera fila, aunque el desembolso sea mayor, que una obra de segunda, por muy económica que esta resulte, ya que la primera no sufrirá altibajos en su precio. Al mismo tiempo, debemos desechar la idea de que para invertir en arte se requieran grandes capitales: a tenor de los datos expuestos, apreciamos la posibilidad de crear una colección en muchos sectores de este mercado, sin desembolsos extraordinarios. 
Lo que se aconseja es un aumento de estos in crescendo, dentro de una estrategia de diversificación de la inversión tradicional. Tanto el coleccionista como el coleccionista-inversor deben asumir que dentro de este mercado la liquidez no siempre es inmediata, y que los rendimientos se obtienen a medio o largo plazo; no se debe por ello buscar una inversión a corto plazo, ya que las obras evolucionan de forma autónoma.

La proliferación y éxito de los grandes fondos de inversión, que exigen importantes cantidades para participar, pues centran sus servicios en la rentabilidad proporcionada por la compraventa de grandes obras maestras, demuestra que no todas las obras de arte actúan como valor refugio, siendo principalmente la calidad de la obra el elemento determinante para alcanzar el éxito financiero. También es cierto que la inversión especulativa con obras de artistas emergentes es igualmente un reclamo interesante para acompañar en la cartera de inversión.

Actualmente, nos sumergimos en una sociedad inmersa en la tecnología en todos los aspectos en lo que esta puede desarrollarse, incluido el mercado del arte. Es por ello que este se ha globalizado, abriéndose a todos los rincones del planeta y permitiendo el acceso a nuevos perfiles de coleccionistas o inversores. Esta expansión, junto con su democratización y su participación en las redes sociales, ha facilitado el acceso de la sociedad al mundo del coleccionismo de arte.

\section{REFERENCIAS}

Artprice. (2017-2020). Annual Report. https://es.artprice.com/ artprice-reports/

Artprice. (2018). Artprice launches its "blue-chip" Art Market index, Artprice $100^{\oplus}$, designed for financiers and investors. Artprice https:// www.artprice.com/artmarketinsight/artprice-launches-its-bluechip-art-market-index-artprice100-designed-for-financiers-andinvestors-2

Baltayan, A. (2020). How to invest in art - Types, pros \& cons, buying \& selling. Art Investment. https://www.moneycrashers.com/ art-investment 
Baumol, W. J. (1986). Unnatural value: Or art investment as a floating crap game. American Economic Review, 76(2), 10-14. https://www.jstor. org/stable/1818726

Citi Private Bank. (2013). Citi Global Financial Database. Citi.

Citi Private Bank. (2020). The global art market and COVID-19. Ed. Citi GPS: Global Perspectives \& Solutions. https://www.privatebank.citibank. com/ivc/docs/Citi-GPS-Art-report-Dec2020.pdf

Deloitte. (2019). Art \& Finance Report 2019. Art Tactic.

Frey, B. (2005). What values should count in the arts? The tension between Economics effects and cultural value [CREMA working paper 200524]. Centre for Research in Economics, Management and the Arts, CREMA.

Frey, B., \& Pommerehne, W. (1989). Muses and markets: Exploration in the economics or the arts. Cambridge.

Frey, B., Luechinger, S., \& Stutzer, A. (2004). Valuing public goods: The life satisfaction approach [CESifo Working Paper, No 1158]. Centre for Economics Studies and ifo Institute (CESifo). http://hdl.handle. net/10419/76476

Karim, H. (2018). Art as investment. futuresmag. http://www.futuresmag. com/2018/07/10/art-investment 9/5/2020

Lawlor, P. (2020). Does investing in art make financial sense? Investec. https:// www.investec.com/en_za/focus/investec-cape-town-art-fair/art-asan-investment.html

McAndrew, C., \& Thompson, R. (2007). Are Presale Art Auction Estimates Unbiased?: Some Affirming Evidence. KUSIN/SMU.

Mei, J., \& Moses, M. A. (2004). Vested Interest and biased price estimates: Evidence from an auction market. The Journal of Finance, 60(5), 24092435. https://doi.org/10.1111/j.1540-6261.2005.00803.x

Parsons, M. (2017, agosto 12). Thinking of investing in art? Read these experts' tips first. The Irish Times. https://www.irishtimes. com/life-and-style/homes-and-property/fine-art-antiques/ thinking-of-investing-in-art-read-these-experts-tips-first-1.3181436

Pérez-Calero-Sánchez, L. (2011). El mercado del arte e intermediarios: Una perspectiva actual. Laboratorio de Arte, 23, 537-550. http:// institucional.us.es/revistas/arte/23/articulo_26.pdf 
Reitlinger, G. (1970). The Economics of Taste. Barrie and Jenkins.

Saatchi. (2016) Annual Report. M \& C Saatchi.

Sánchez-Vasconcellos, A., Vico, A., \& Palomo, J. (2020). Los puertos francos y su influencia en el mercado del arte. La Albolafia: Revista de Humanidades y Cultura, 19, 211-238.

Thompson, E., Berger, M., Blomquist, G., \& Allen, S. (2008). Valuing the Arts: A Contingent Valuation Approach. Journal of Cultural Economics, 26, 87-113. https://doi.org/10.1023/A:1014426202110

Vico, A., Palomo, J., \& Laguna, P. (2015). La rentabilidad de las obras de arte: estudio de los entornos propicios para la venta de bienes artísticos y de colección. Dykinson.

Vico, A., \& De-la-Fuente, P. (2018). La juventud en el mercado del arte. Revista de Estudios de Juventud, 118,173-186.

Sotheby's. (2020). Sotheby's - Mei Moses Index \& Reports, 2019-2020. https:// www.sothebys.com/en/the-sothebys-mei-moses-indices

\section{Referencias web recomendadas}

https://www.investing.com/studios/article-1012

https://forbes.es/empresas/8295/9-razones-por-las-que-invertir-en-arte/6/ http://www.artfundassociation.com/_what_are_art_funds/basic_af.html https://itsartlaw.org/2015/05/19/art-investment-funds-intro/ https://observer.com/2014/05/dollars-on-the-wall-a-booming-art-marketattracts-investors/\#ixzz3Zyu3COXX

https://www.investmentnews.com/masterworks-is-opening-fine-art -investing-to-the-masses-2-76258 